One other large mass was found weighing I 54 pounds ( 69.853 kilos). This is also deeply pitted. A mass weighing approximately 40 pounds (18.144 kilos) was broken in pieces with a trip hammer, and it was in cutting one of the fragments of this mass that diamonds were discovered (Fig. 2).

Besides these masses of considerable size a careful search made by myself with the assistance of five men was rewarded by the discovery of 108 smaller masses. Twenty-three others were also discovered, making a total of $\mathrm{I} 3 \mathrm{I}$ small masses, ranging in weight from 1 ib of an ounce (1.79 grm.) to 6 pounds 10 ounces ( $3^{\circ} 006$ kilos). ${ }^{1}$ A brownish-white, slightly botryoidal coating, found on a number of the meteorites, is probably aragonite.

A thorough examination of many miles of the plain proved that the car-load of iron existed only in imagination. Accompanying the pieces found at the base of the "crater" were oxidized and sulphuretted fragments which a preliminary examination has shown are undoubtedly of meteoric origin. About 200 pounds (90.718 kilos) of these were secured, from minute fragments up to 3 pounds I 4 ounces (r.757 kilos). These fragments are mostly quite angular in character, and a very few show a greenish stain, resulting probably from the oxidation of the nickel. This oxidized material is identical in appearance with an incrustation which covers some of the iron masses and partially fills some of the pits.

Composition.-After obtaining the meteorite I was unable to return to Philadelphia for some time, and therefore sent a fragment of the 40-pound mass (18.144 kilos) to Prof. G. A. Koenig for examination. Prof. Koenig was compelled to leave town before this examination was completed. I take the following, therefore, from his letters to me, and from an account furnished the daily Public Ledger by Dr. E. J. Nolan, Secretary of the Academy of Sciences, of a preliminary notice made by Prof. Koenig, June 23, before the Academy of Natural Sciences of Philadelphia. In this account he says :-

"In cutting the meteoric iron for study it had been found of an extraordinary hardness, the section taking a day and a half, and a number of chisels having been destroyed in the process. When the mass, which on the exterior was not distinguished from other pieces of meteoric iron, was divided, it was found that the cutting apparatus had fortunately gone through a cavity. In the attempt to polish the surface, so as to bring out the characteristic Widmannstättian figures, Dr. Koenig received word that the emery wheel in use had been ruined.

"On examination, he then found that the exposed cavities contained diamonds which cut through polished corundum as easily as a knife will cut through gypsum. The diamonds exposed were small, black, and, of course, of but little commercial value, but mineralogically they are of the greatest interest, the presence of such in meteorites having been unknown until 1887 , when two Russian mineralogists discovered traces of diamond in a meteoric mixture of olivine and bronzite. Granules of amorphous carbon were also found in the cavity, and a small quantity of this treated with acid had revealed a minute white diamond of one-half a millimetre, or about $1 / 50$ of an inch in diameter. In manipulation, unfortunately, this specimen was lost, but others will doubtless be obtained in the course of investigation. The minerals troilite and daubreelite were also found in the cavities. The proportion of nickel in the general mass is 3 per cent., and the speaker was not as yet able to account for the extraordinary hardness apart from the presence of the diamonds in the cavities."

I October 18.- During September I received three additional large masses weighing respectively 632,506 , and 145 pounds (or $286^{\circ} 678,229^{\circ} 5^{\circ} 16$ and $65^{\circ} 77 x$ kilos). The two latter were each perforated with three holes. A number of smaller masses up to 7 pounds ( $3^{\circ} 175$ kilos) were discovered by covered with grass and earth - A E. F.

NO. I I 56, VOL. 45]
Prof. Koenig in a letter to me gives the following points as definitely known :-

"( (I) Diamonds, black and white, established by hardness and indifference to chemical agents. (2) Carbon in the form of a pulverulent iron carbide occurring in the same cavity with the diamonds. The precise nature of this carbide, whether containing hydrogen and nitrogen, is not ascertained, except in so far that after extracting all iron by nitro-hydrochloric acid the black residue goes into solution with deep brown colour upon treating it with potassium or sodium hydrate. From this solution acids do not precipitate anything. (3) Sulphur is not contained in the tough malleable portion of the meteorite, but in the pulverulent portion. (4) Phosphorus is contained in the latter, and not in the former. (5) Nickel and Cobalt in the proportion of $2: \mathrm{I}$ are contained in both parts nearly equally. (7) Silicon is only present in the pulverulent portion. (8) The Widmannstättian figures are not regular. (9) The iron is associated with a black hydroxide containing $\mathrm{Fe}, \mathrm{Ni}, \mathrm{Co}, \mathrm{P}$, in the ratio of the metallic part, and therefore presumably derived by a process of oxidation and hydration of the latter."

Conclusions. - As this meteoric iron contains only 3 per cent. of nickel, while that from the Santa Catarina Mountains, 30 miles $(48.28$ kilometres) south-east of Tucson and 215 miles ( 346 kilometres) from this locality, contains from 8 to 9 per cent., according to the analysis of Brush and Smith, they are quite distinct, although somewhat alike in external appearance. They also somewhat resemble the Glorietta meteoric irons from about 300 miles (482 8 kilometres) to the east-north-east, in New Mexico. These contain II'I 5 per cent. of nickel.

The most interesting feature is the discovery for the first time of diamonds in meteoric iron. ${ }^{1}$ This might have been predicted from the fact that all the constituents of meteoric iron have been found in meteoric stones, and vice vers $\hat{a}$, although in different proportions.

The incrustation of what is probably aragonite snown by some of the masses has rarely been noticed (I find two records by J. Lawrence Smith which he states to be unique, and both of these were from regions south of this one) The incrustation is especially interesting as showing that the meteoric irons must have been embedded a long time, as the formation of aragonite would be exceedingly slow in this dry climate.

The remarkable quantity of oxidized black fragmental material that was found at those points where the greatest number of small fragments of meteoric iron were found would seem to indicate that an extraordinarily large mass of probably 500 or 600 pounds (226.796 or $272 \cdot 165$ kilos) had become oxidized while passing through the air, and was so weakened in its internal structure that it had burst into pieces not long before reaching the earth.

\section{THE SEVERE GALE OF NOVEMBER II.}

THE storm which traversed England on November II was one of the most severe of recent years. It resulted in considerable loss of life and property at sea on our coasts, and did a large amount of damage on land.

The weather over England at the commencement of the month was dry and fine, and the conditions were those known as anticyclonic, the barometer on November 5 having exceeded $30^{\circ} 7$ inches over a great part of the United Kingdom. On November 8, the type of weather became cyclonic, and disturbances were skirting close to our coasts from off the Atlantic, south-westerly gales being experienced in the Hebrides and in the west of Ireland;

2 Attention may be called to the discovery by Haidinger (1846) of cubic crystals of a graphitic carbon in the Arva meteoric iron, and also of somewhat similar crystals from the Youngdegin (West Australia) iron, described by Fletcher ( 1887 ) under the name of cliftonite. Both have been regarded as pseudomorphs after diamond. 
whilst on the following day unsettled weather spread to other parts of the United Kingdom, and rain was heavy and persistent over the south of England.

The daily weather report issued by the Meteorological Office at 8 o'clock on the morning of the roth showed that the winds were westerly and south-westerly over the whole of the British Islands under the influence of a storm area situated off the north-west of Scotland, the readings at our extreme northern stations being $29^{\circ} \mathrm{I}$ inches ; but a fresh fall of the barometer was already in progress at Valentia, and the wind had there backed to south-southwest. The report added: "The new depression which is approaching our western coasts is at present too far away to enable us to judge of its size or depth." The telegrams received by the Meteorological Office at 2 o'clock indicated the approach of a serious disturbance; the barometer was
Islands, and gales were blowing in most parts of the country. The cyclonic circulation of the winds was complete in our islands, the direction being northerly in Ireland; westerly and south.westerly over the Channel and the south of England, southerly on our east coasts, and easterly in Scotland and the northern portion of the Kingdom. The barometer gradients were very steep in the English Channel, as well as in the south-western and south-eastern districts ; and at Scilly force I I of Beaufort's notation was reported from the north-west. At many of the English stations the fall of the barometer since 6 o'clock the previous evening exceeded $0^{\circ} 9$ inch, and at Hurst Castle it amounted to an inch, whilst in several places in the south and west the rainfall exceeded an inch in the preceding 24 hours. The gale continued to rage during the day, and at 2 o'clock in the afternoon the

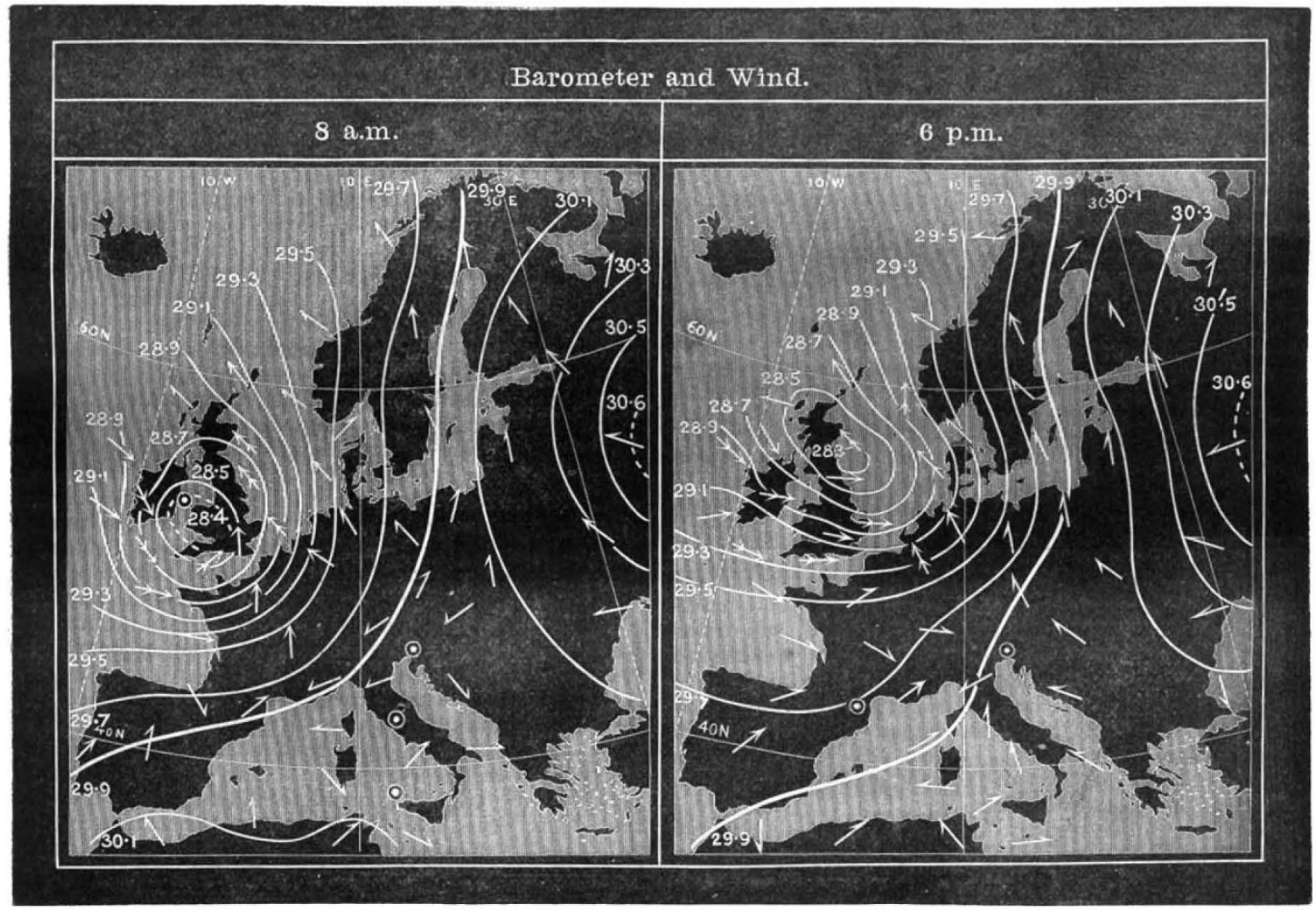

Diagram to Illustrate the Severe Gale of Wednesday, November ir, i8gr.

The barometer is expressed by isobars, the pressure corresponding to each line being given in inches and tenths. The winds are shown by arrows which are drawn flying with the wind. $\odot=$ a calm $; \longrightarrow=$ a light $\rightarrow$ or moderate wind $: \longrightarrow=a$ fresh or strong breese ; $\rightarrow \rightarrow=a$ gale

alling rapidly at the south-western stations, and the fall had now extended even to London, and the wind had backed over the whole Kingdom. The evening reports indicated a still further advance of the storm area towards our islands, and the trend of the isobars over the southwestern portion of the Kingdom showed that the centre of the disturbance was not far distant to the south-westward, whilst moderate south-easterly gales were blowing at the entrance of the English Channel.

The conditions on the morning of the inth are pictured in the diagram for 8 o'clock, obtained from the weekly weather report of the Meteorological Office, and from this it will be seen that the storm area was central over Pembrokeshire, the lowest reading being 28.36 inches at St. Ann's Head, whilst the mercury was below 29 inches over the entire area of the British NO. I I 56, VOL. 45] force of the wind at Dungeness was reported as 12 of Beaufort's notation, which is the extreme limit of the scale, and is equivalent to a hurricane, the lowest barometer reported to the Meteorological Office at this time being $28^{\circ} 34$ inches at Shields. At 6 o'clock on the IIth, the central area of the storm had passed to the eastward of our coasts, as shown by the diagram for that hour, the core or heart of the storm not being far distant from Shields, where the barometer was standing at 28.31 inches, which is apparently the lowest reading recorded in the British Islands during the gale. Strong westerly and north-westerly gales were still blowing over the greater part of the United Kingdom, and the succeeding night was very boisterous, although the gale had everywhere subsided before 8 o'clock on the following morning. 
The Meteorological Council have very kindly permitted the use of the Observatory records and other documents in their possession, which are more in detail than the eye observations made at the telegraphic reporting stations which furnish data for the daily weather reports.

The following table shows the hourly velocity of the wind as obtained from the anemometrical records. All velocities of 35 miles and upwards are given, and when so strong a wind is recorded at any Observatory, the velocity is given at the other Observatories, although less than 35 miles an hour.

Velocity of the Wind by Anemographs.

\begin{tabular}{|c|c|c|c|c|c|c|}
\hline \multicolumn{2}{|c|}{ Time. } & Valentia. & Falmouth. & Holyhead. & Kew. & Aberdeen. \\
\hline \multicolumn{2}{|c|}{ November $\pi$. } & & & & & \\
\hline \multicolumn{2}{|c|}{$\begin{array}{l}\text { r a.m. } \\
\text {. }\end{array}$} & 28 & 28 & $4 I$ & 25 & 16 \\
\hline 2 & ," & 34 & $3 \mathrm{I}$ & 41 & 27 & $2 \mathrm{I}$ \\
\hline 3 & $"$ & 37 & 24 & 38 & 26 & 20 \\
\hline 4 & ", & 41 & 23 & 33 & 20 & 27 \\
\hline 5 & ", & 39 & 21 & $3 \mathrm{I}$ & 28 & 34 \\
\hline 6 & ", & 38 & $2 \mathrm{I}$ & 20 & 34 & 35 \\
\hline 7 & ,, & 34 & 25 & 13 & $3 I$ & 37 \\
\hline 8 & , & 32 & 50 & 2 & 31 & 40 \\
\hline 9 & ", & 34 & 62 & 17 & 32 & 44 \\
\hline 10 & ," & 33 & 56 & 36 & 35 & 47 \\
\hline II & & 28 & $5 \mathrm{I}$ & 57 & 30 & 43 \\
\hline \multicolumn{2}{|c|}{ Noon. } & 33 & 43 & 59 & 25 & 44 \\
\hline \multicolumn{2}{|c|}{ I p.m. } & 35 & 43 & 58 & 32 & $4 i$ \\
\hline \multicolumn{2}{|c|}{2,} & 34 & 34 & 52 & 45 & 39 \\
\hline \multicolumn{2}{|c|}{3,} & 34 & 30 & 43 & 43 & 39 \\
\hline \multicolumn{2}{|c|}{$4 \quad$} & 32 & 33 & 48 & 35 & 36 \\
\hline \multirow{2}{*}{$\begin{array}{l}5 \\
6\end{array}$} & & 24 & 20 & 48 & 29 & 30 \\
\hline & ," & 17 & 24 & 42 & 29 & 21 \\
\hline \multirow{2}{*}{$\begin{array}{l}7 \\
8\end{array}$} & ," & 17 & 20 & 46 & 29 & 22 \\
\hline & ", & 20 & 18 & 39 & 26 & I 7 \\
\hline \multirow{2}{*}{$\begin{array}{r}9 \\
10\end{array}$} & ", & 15 & I6 & 46 & 21 & II \\
\hline & & 18 & 12 & 42 & 17 & 13 \\
\hline \multicolumn{2}{|c|}{ II " } & 27 & II & 40 & 12 & 22 \\
\hline \multicolumn{2}{|c|}{$\begin{array}{l}\text { II I '’ } \\
\text { Midnight. }\end{array}$} & 20 & 16 & 36 & 15 & 23 \\
\hline
\end{tabular}

From the table it will be seen that the gale did not continue over the United Kingdom for more than twentyfour hours, and at Falmouth and Holyhead, where the highest velocities were obtained, the wind only exceeded 50 miles an hour - a fresh gale of Beaufort's notationfor four hours; whilst the maximum hourly velocity at any observatory was 62 miles, registered at Falmouth at 9 o'clock in the morning. These velocities, although a fair index of the severity of the gale, give no idea of the violence of the gusts or squalls.

The photographic registrations of the barometer show that at Valentia the first fall for the gale set in at I a.m., Ioth, when the mercury was standing at 29.5 inches, and the lowest reading was not reached for more than twentyfour hours later, the minimum being 28.78 inches at 2. Io a.m., IIth. The fall at Valentia only exceeded the rate of 0.05 inch per hour for two hours, and the subsequent rise there was not very brisk; the wind force, however, at Valentia throughout the storm did not exceed a moderate gale. At Falmouth, the barometer commenced to fall at $8 \mathrm{a} . \mathrm{m}$., roth, and by I a.m., IIth, the mercury had decreased an inch, whilst the lowest reading was 28.37 inches at 5 a.m., IIth. The subsequent rise was very slight at first, but after 8 a.m., I Ith, it amounted to 0.15 inch per hour. At Kew the first fall of the barometer is shown at I I a.m., I oth, just ten hours subsequent to Valentia; and the lowest reading was $28{ }^{\circ} 47$ inches at I I. 5 a.m., I Ith, only nine hours later than Valencia. The fall did not amount to $O^{\circ} \mathrm{I}$ inch per hour, but the subsequent rise was 0.15 inch per hour from $\mathrm{I}$ to $3 \mathrm{p} . \mathrm{m}$. The wind did not veer till after I p.m., and then only to westsouth-west from south-south-west. The hourly velocity of the wind at Kew evidently affords but little illustration of the violence of the gale, since the maximum velocity was only 45 miles, which occurred at 2 p.m.; whilst at Greenwich the pressure anemometer registered $3 \mathrm{I}^{\circ} 5 \mathrm{lbs}$. on the square foot at $235 \mathrm{p} . \mathrm{m}$. At Fort William the barometer commenced to fall at II.30 a.m., Ioth, and the lowest reading was 28.48 inches at 3.53 p.m., I Ith. At Aberdeen the fall of the barometer set in at 7.45 p.m., Ioth, and the minimum was 28.38 inches at $9 \mathrm{p} \mathrm{m}$., IIth; whilst here the wind changed suddenly from south-east by east to west by north at IO I 5 p.m., IIth.

The ship Khyber, Captain W. Peterkin, keeping a log for the Meteorological Office, felt the first influence of the cyclonic weather system at midnight, 9 th, in lat. $49^{\circ} 30^{\prime} \mathrm{N}$., and long. $13^{\circ} \mathrm{W}$., about 300 miles to the west of Land's End, when a moderate south-west wind was blowing, and the barometer stood at 29.64 inches. The wind afterwards changed through south, south-east, east, and north-east, and the centre of the disturbance passed to the south of the vessel, being nearest to the ship at about Io p.m., loth, when the barometer was 28.71 inches, and the wind was blowing a fresh gale from north-northeast, the ship being in lat. $49^{\circ} 40^{\prime} \mathrm{N}$., and long. $12^{\circ} 20^{\prime} \mathrm{W}$. This vessel shows that the wind did not attain gale force until after the centre had passed to the east of the ship, but with a rising barometer she experienced a very strong northerly gale.

The observations from the Khyber, considered with those obtained from stations in the United Kingdom, show that the storm system travelled across the area of the British Islands at the rate of about 34 English miles per hour; but the rate of progress was slackening decidedly after it had passed over the centre of England, and on reaching the North Sea it passed away very slowly to the northward.

The exceptional features of the storm were the strong gales experienced in the English Channel and over the southern portion of the Kingdom, accompanied by a terrific sea, the latter being doubtless greatly aggravated owing to the heavy westerly wind setting up the Channel, also the low barometer which occurred in the southern part of the country. In the neighbourhood of London the barometer fell to 28.47 inches, and there have only been seven years since I8I in which the reading has fallen lower, the absolutely lowest corrected reading during the last eighty years in the vicinity of London being 28.02 inches on January $29,1814$.

The influence of this storm area had not passed away from our islands before an entirely fresh disturbance was seen to be approaching the Irish coasts, and at Valentia a fresh fall of the barometer was in progress after 7.50 p.m. on the IIth, the barometer having only previously risen to $29^{\circ} 20$ inches. The mercury subsequently fell to 28.36 inches at 6.20 p.m., 12 th, which is more than 0.4 inches lower than during the gale of the IIth; and the wind attained the velocity of 58 miles an hour, and was above 5o miles an hour for ten hours, from I to Io p.m. At Falmouth the wind attained the hourly velocity of 47 miles at 6 p.m., I 2 th, and at Holyhead 45 miles at noon, I 2 th ; but at Kew and Aberdeen the wind did not increase beyond a fresh breeze.

The sudden manner in which this second disturbance collapsed, after assuming very threatening proportions, is of considerable interest, in so far as it affords a good illustration of the extreme difficulty experienced at times in the weather forecasting for our islands; the present position of science affording no explanation why the one storm should traverse our islands, and the other prove entirely abortive after reaching the western stations.

ChAS. HARDING.

\section{NOTES.}

ThE Duke of Devonshire, of whose death every one was sorry to hear, maintained throughout life the interest in science which had been fostered by his studies as an undergraduate at

NO. I I 56 , VOL. 45] 